\title{
Servicio civil en Chile, análisis de los directivos de primer nivel jerárquico (2003-13)'
}

\author{
Bastián González-Bustamante \\ Universidad de Santiago de Chile / Facultad de Administración y Economía \\ Santiago de Chile - Chile \\ Alejandro Olivares L. \\ Universidad de Chile / Instituto de Asuntos Públicos \\ Santiago de Chile - Chile \\ Pedro Abarca \\ Servicio Nacional de Capacitación y Empleo / Unidad de Desarrollo Estratégico \\ Santiago de Chile - Chile \\ Esteban Molina \\ Topoland Ingeniería y Compañia Limitada / Unidad de Calidad y Control de Gestión \\ Los Andes - Chile
}

\begin{abstract}
Este artículo analiza los principales factores que condicionan la selección de un directivo público de primer nivel jerárquico en Chile con base en una perspectiva de corte sociológico y el uso del concepto especies de capital. El trabajo realiza un recorrido teórico y descriptivo sobre la modernización del Estado y la profesionalización de la gestión pública en Chile. Posteriormente con una muestra de 45 casos correspondientes a altos directivos nombrados durante el período 2003-13, se trabaja con modelos de regresión logística para determinar los factores que condicionan la selección de estos funcionarios. Se llega a la conclusión que el capital político no es un factor que favorece la selección del actor.
\end{abstract}

Palabras clave: servicio civil; alta dirección pública; tecnocracia; Chile.

Serviço civil no Chile, análise dos diretivos de primeiro nível hierárquico (2003-13)

Este artigo analisa os principais fatores que influenciam a escolha de um diretivo público de primeiro nível hierárquico no Chile, com base numa perspectiva sociológica e no uso do conceito espécies de

DOI: http://dx.doi.org/10.1590/0034-7612145767

(c) (i)

Artículo recibido en 7 feb. 2015 y aprobado en 18 nov. 2015.

${ }^{1}$ Agradecemos al proyecto Fondecyt 1100877 (Alfredo Joignant, investigador responsable) por otorgar soporte para una versión preliminar de este trabajo. Además agradecemos especialmente a Rodrigo Egaña, Adrián Albala y Antoine Maillet por su lectura crítica y valiosos comentarios. 
capital. A pesquisa realiza um rastreio teórico e descritivo sobre a modernização do Estado e a profissionalização da gestão pública no Chile. Logo, com uma amostra de 45 casos relativos aos altos funcionários públicos nomeados durante o período 2003-13, usaremos modelos de regressão logística para determinar os fatores que influenciam na seleção desses funcionários. Contudo, o artigo conclui que o capital político não é um fator que favorece a seleção do ator.

Palavras-chave: serviço civil; alta direção pública; tecnocracia; Chile.

Civil service in Chile, analysis of senior civil servants on the top rung of the hierarchy (2003-13) This article analyses the main factors that affect the election of a high civil servant in the first level of hierarchy in Chile, according to a sociological perspective using the capital species concept. This paper provides a theoretical and descriptive travel on State modernization and professionalization of public management in Chile. Later, with a sample of 45 cases regarding high civil servants designated during the period of 2003-13, a maximum likelihood logit models were performed to determine the factors that influence the selection of these civil servants. It concludes that political capital is not a factor that gives advantage in the selection.

Keywords: civil service; high public management; technocracy; Chile.

\section{Introducción}

La discusión sobre burocracia, tecnocracia y procesos políticos, ha sido central para diferentes disciplinas de las ciencias sociales, particularmente para las vinculadas a la gestión y administración (García-Pelayo, 1982). Como consecuencia de este debate y de la implementación de los procesos de modernización del sector público, se suele pensar que un servicio civil autónomo, ${ }^{2}$ alejado de pugnas y conflictos políticos, permite garantizar buenos niveles de eficiencia en la gestión gubernamental, disminuyendo además el riesgo de casos de corrupción.

Siguiendo a Ballart y Ramió (2000) y Ramió y Salvador (2005), los servicios civiles pueden ser clasificados en torno a dos díadas. La primera pone en tensión el grado de politización frente al grado de profesionalización. La segunda díada pone en contraposición el nivel de apertura del sistema frente al nivel de cierre que éste presenta. La tensión entre politización y profesionalización tiene directa relación con la priorización de la confianza política sobre los méritos profesionales en los procesos de reclutamiento del funcionariado. Por otra parte, la tensión entre los diversos grados de apertura tiene relación con el hecho de que los sistemas cerrados se basan en carreras de por vida, lo que implica tácitamente que los funcionarios deben necesariamente poseer habilidades polivalentes y además adecuarse a las distintas necesidades y cambios a lo largo de su carrera. Frente a esto los sistemas abiertos se basan en una selección que prioriza la especialización.

\footnotetext{
${ }^{2}$ Se entiende servicio civil como: “[...] sistema de gestión del empleo público y los recursos humanos adscritos al servicio de las organizaciones públicas, existente en una realidad nacional determinada” (Echebarría, 2006:4).
} 
Los sistemas donde predomina la politización son similares a la administración pública estadounidense del siglo XIX basada en un sistema de botín (spoil system) o al sistema de cesantías español de la misma época. Estos sistemas de botín implican la renovación del funcionariado público después de las elecciones, ya que el partido —o coalición- vencedor recompensa a sus militantes y adherentes con nombramientos en reparticiones públicas (Ramió y Salvador, 2005). El spoil system de antaño asume formas contemporáneas, una de ellas se refiere a un sistema de circuito abierto que implica selección con base en confianza política con criterios profesionales subsidiarios. Otra forma contemporánea es el sistema de circuito cerrado referido a la combinación de méritos y confianza política con base en nombramientos directos, mucho más similar al sistema clásico (Quermonne, 1995; Ramió y Salvador, 2005).

El spoil system se relaciona con los sistemas de servicio civil basados en clientelismo descritos por Grindle (2012). El surgimiento de los sistemas de servicio civil impuso nuevas "reglas de juego" en el mundo político, ante esto los agentes se acomodaron para obtener posiciones dentro del Estado: en Prusia y Japón, por ejemplo, predominaron reformas con hincapié en la educación como medio para entrar al servicio público, situación que implicó que las élites aristocráticas resultasen privilegiadas, ya que tenían mayor facilitad para acceder a una buena educación (Grindle, 2012).

Lo anterior se vincula con las estrategias de reproducción social mediante las cuales un individuo —o familia - busca asegurar o mejorar su posición en el espacio social, contexto en el cual la reconversión de capital económico en capital cultural emerge como una estrategia clásica de reproducción (Bourdieu, 2011). Esta situación es palpable en los sistemas de servicio público que surgieron en Gran Bretaña o Francia, casos en los cuales el clientelismo emergió como un mecanismo para garantizar que las élites accedieran a cargos públicos y así pudiesen asegurar su bienestar (Grindle, 2012).

Los sistemas de botín han contribuido a generar brechas entre el mundo político y el mundo de los funcionarios profesionales, sean éstos burócratas, tecnócratas o altos directivos públicos. Cada uno de estos términos se asocia a diferentes perfiles de funcionarios públicos profesionales, cada cual con distintos recursos y capitales. ${ }^{3}$ Es importante señalar que el uso de distintos términos para referirse a los funcionarios públicos también da cuenta de distintas formas de ver la relación entre política y administración, ya que, cada término tiene asociada una ontología específica sobre dicha relación. Tradicionalmente los burócratas de alto nivel han sido denominados "mandarines", esto en el contexto de una visión weberiana donde la imposibilidad de remoción del funcionario generaba una captura de los burócratas sobre los agentes políticos. Por otro lado, el término tecnócrata suele ser usado para referirse a burócratas con altos niveles de recursos técnicos, mientras alto directivo público es más propio del enfoque de la Nueva Gestión Pública (NGP). El tecnócrata suele generar vínculos con el mundo político, intentando penetrar en spoil systems de circuito abierto, mientras que el alto directivo público obedece a una lógica de agencia que implica delegación y autonomía.

\footnotetext{
${ }^{3}$ Concepto que sigue la tradición de la sociología política francesa (Bourdieu, 1980/2009, 1997/2011).
} 
En este contexto, cabe preguntarse sobre la asentada idea acerca de los beneficios de la existencia de un servicio civil autónomo alejado del poder político. ¿Es realmente posible la existencia de funcionarios públicos de alto nivel alejados e independientes del poder político? Esta pregunta es relevante pues la idea de un cuerpo de altos directivos separados de la política y la burocracia clásica ha comenzado a ser vista como una pieza fundamental para las reformas del servicio civil en la región (Ramos y Scrollini, 2013).

Este trabajo realiza un análisis de los procesos de selección de los directivos públicos que han sido nombrados en las reparticiones que dependen de los principales ministerios chilenos. Se realiza un análisis descriptivo de los concursos realizados y se analizan los factores que determinan la selección en un cargo de primer nivel jerárquico en el Sistema de Alta Dirección Pública (SADP) en Chile. Los factores que se analizan son sexo, posesión de capital político, nivel educacional (capital cultural institucionalizado), sector de procedencia con respecto a la ocupación anterior (público-privado), y vinculaciones a universidades tradicionales. En resumen, el trabajo se enfoca en los procesos de selección de directivos para cargos del primer nivel jerárquico en servicios dependientes de importantes ministerios. La pregunta que se busca responder es, ¿cuáles son los principales factores que intervinieron en el nombramiento de estos funcionarios? Responder esta interrogante permitirá evaluar el rol del SADP en los procesos de nombramientos de altos directivos de áreas altamente sensibles para los gobiernos.

En el siguiente apartado se realiza un recorrido teórico-descriptivo sobre la relación entre política y administración pública, la modernización del Estado y la profesionalización de la gestión pública en Chile. En una primera instancia se da cuenta del contexto y los claroscuros que rodean a la profesionalización de la función ejecutiva en el caso chileno, posteriormente se aborda el surgimiento del SADP. El segundo apartado es de carácter metodológico y ofrece detalles sobre los datos con los cuales se trabaja. En el tercer apartado se presentan resultados de orden descriptivo y distintos modelos logísticos que permiten evaluar los factores determinantes en el nombramiento de altos directivos públicos. Finalmente se encuentra el apartado de conclusiones y discusión.

\section{La modernización del Estado y la profesionalización de la gestión pública en Chile}

\subsection{Política y administración pública, un debate de larga data}

La relación entre política y administración pública ha dado pie a un debate de larga data, donde el paradigma tradicional, que implica una separación entre ambas esferas, ha sido fuertemente cuestionado. Si bien durante la primera mitad del siglo XX existió una visión de la política y la administración como esferas separadas en el contexto de la actividad gubernamental, desde la década de 1980 en adelante, la participación de las instituciones en la actividad política y la influencia de las élites en las decisiones administrativas y burocráticas 
ha sido un área de estudio que ha despertado gran interés entre académicos e investigadores. En esta línea, las perspectivas neoinstitucionalistas dan cuenta de las redes entre funcionarios públicos y políticos profesionales (Ansell, 2006; March y Olsen, 2006; Rhodes, 2006), particularmente a través del concepto de redes de políticas públicas en la perspectiva de enfoques institucionalistas de redes. Ansell (2006) y más tempranamente Heclo y Wildavsky (1974) abordaron los vínculos entre funcionarios y políticos como factores que regulan los procesos de toma de decisiones dentro de las instituciones. En este sentido, el estudio de la élite burocrática, tecnocrática o administrativa, resulta importante para comprender los sistemas políticos modernos, ya que parece un hecho que un alto nivel profesionalización de la política se relaciona fuertemente con la calidad de la ejecución de las políticas públicas (Alcántara, 2013). Así emergen figuras como los technopols, agentes que presentan una gran acumulación de recursos técnicos y capital político a la vez. ${ }^{4}$

En este marco se encuentran diversos modelos de sistemas de servicio civil y cómo la profesionalización y modernización de la gestión pública han condicionado el avance de aquellos modelos. En América Latina es posible apreciar distintos modelos de servicio civil, de acuerdo a Ramió y Salvador (2005) existe una variedad de situaciones intermedias que no poseen un modelo determinado pero si ciertos servicios altamente profesionalizados, los cuales generalmente corresponden a las áreas diplomáticas. Por otra parte, hay una serie de países que en la última década han intentado llevar adelante de forma parcial sistemas de servicio civil (e.g., Bolivia, México, República Dominicana, entre otros). Por último, ciertos países que históricamente poseían un modelo de servicio civil que fue pulverizado por los regímenes militares en la década de 1980, actualmente impulsan cambios y revisiones a la institucionalidad vigente. En esta última categoría es donde se ubica el caso chileno.

De acuerdo a Grindle (2012), la consecución de los sistemas de servicio civil en América Latina ha estado vinculada al surgimiento de ventanas de oportunidad — apelando al concepto de Kingdon (1984) — en la política doméstica de cada país, sin embargo, estas reformas no han eliminado del todo los sistemas de clientelismo y patronazgos existentes desde el siglo XIX y XX. Brasil, por ejemplo, posee un servicio a cargo del Departamento Administrativo de Servicio Público, el más antiguo del continente, que surgió después de la crisis económica de la década de 1930 (Grindle, 2012). Aquí se advierte la construcción de un sistema de alta dirección pública y servicio de carrera sin la deconstrucción del clientelismo.

\subsection{La profesionalización de la gestión pública en el caso chileno}

El servicio público chileno durante gran parte del siglo XX se enmarca en las lógicas de los spoil systems. Con el golpe de Estado en 1973 y el posterior régimen autoritario se configuró

\footnotetext{
${ }^{4}$ Concepto utilizado ampliamente por Joignant (2011b), Delamaza (2011) y González-Bustamante (2013) en el marco del estudio de la élite política gubernamental chilena.
} 
un escenario que permitió la imposición de políticas de transformación neoliberales, las cuales crearon nuevos mercados disminuyendo significativamente el tamaño del Estado. ${ }^{5}$ Esta situación limitó fuertemente el proceso de profesionalización de la gestión pública. Durante los 17 años sin democracia, los militares realizaron los nombramientos de altos cargos con absoluta discrecionalidad, situación que permitió, siguiendo la lógica de Grindle (2012), la supervivencia del clientelismo durante los años de dictadura.

Una vez en democracia (1990 en adelante) existen dos elementos que condicionan el proceso de profesionalización de la gestión pública chilena. Por un lado, la fuerte influencia de la NGP, que se ha transformado en corriente principal para el estudio de estos temas. ${ }^{6}$ Por otro lado, la relación de los altos directivos con su contraparte en el contexto de la interacción política-administración, es decir, su relación con los agentes políticos o élite política. Este segundo elemento ha sido tratado de forma indirecta en los trabajos sobre modernización y SADP en Chile.

Sobre la fuerte influencia del paradigma de la NGP cabe señalar que fue primordial para las reformas del Estado y su administración, las cuales principalmente implicaron el tránsito hacia una lógica de funcionamiento empresarial-gerencial. En este contexto, algunos consideran que la NGP ha viabilizado el modelo neoliberal de Estado (Ardila, 2003; Vicher, 2009). Desde esta perspectiva, más bien alejada de la corriente principal, el caso chileno sería un verdadero emblema de aquella adaptación forzosa del modelo neoliberal al Estado usando la NGP como piedra angular.

Bajo el paradigma de la NGP se desarrolla una lógica de separación entre políticos y administradores. Se propone una delimitación entre las funciones de los políticos y los burócratas. Mientras el político es responsable por los resultados, el burócrata es responsable por los productos (outputs) que llevan a los resultados (outcomes) (Ramos, Scrollini y Solórzano, 2012). Cumplir con aquel pacto es particularmente difícil para las administraciones latinoamericanas, pues éstas, de acuerdo a Ramos, Scrollini y Solórzano (2012), se caracterizan por tradiciones administrativas de corte napoleónico, en las cuales existe una fuerte resistencia cultural a figuras externas al entorno político.

El caso chileno presenta un choque de identidades. Se funda con base en premisas de la NGP, tanto así que Costa y Waissbluth (2007) reconocen en las empresas privadas a los mejores socios del sistema, básicamente porque juegan un rol muy importante en el proceso de head hunting. A pesar de lo anterior no se generan relaciones contractuales entre el Estado y los altos directivos que permitan aplicar una lógica de agencia. Esta falta de libertad en la gestión junto con el hecho de que la decisión final con respecto al nombramiento siga siempre en manos de la autoridad competente, pudiendo ésta solicitar la renuncia del alto directivo

\footnotetext{
${ }^{5}$ Para más detalles al respecto véase Maillet (2013) y Gárate (2012).

${ }^{6}$ Véase Costa y Waissbluth (2007), Lambertini y Silva (2009), Pliscoff (2008), y Waissbluth y Inostroza (2006). También existe diversa literatura que critica el enfoque de la NGP; véase Guerrero (2009) y Kim (2007).
} 
cuando lo desee, hace que nunca se rompa la subordinación de los aparatos administrativos al gobierno representativo.

Es en este punto donde entra en juego el segundo elemento mencionado al inicio de este apartado: la élite política y su relación con la alta dirección. La relación entre los políticos y los altos directivos en Chile ha sido tratada de forma tangencial en los trabajos desarrollados sobre modernización y SADP, limitándose a generalidades. La configuración de la élite política chilena es un proceso que se encuentra estrechamente ligado a la reconstrucción del campo político en el marco del proceso de recuperación democrática en la década de 1980. El período entre los años 1990 y 2010, correspondiente a los cuatro gobiernos de la Concertación, se caracteriza por el dominio de una élite tecnocrática con gran influencia en los asuntos públicos. Esta élite estaba compuesta principalmente por profesionales jóvenes con estudios en el extranjero, específicamente en universidades estadounidenses (Silva, 2009).

Es importante tener en consideración que la redemocratización chilena se da en el contexto de una transición pactada (Godoy, 1999), con enclaves autoritarios (Garretón, 1997, 1999) y enclaves de transición (Siavelis, 2009). Este panorama generó fuertes incentivos para la adopción de políticas tecnocráticas (Silva, 2009). En esta línea, Delamaza (2011) señala que la reproducción de la élite política chilena fue dominada durante el período 1990-2010 por la expansión de la tecnopolítica, debido al incremento de legitimidad de individuos con perfiles tecnocráticos. Además el arreglo constitucional condicionó el proceso de reconstrucción del campo político, abriendo un amplio espacio en el aparato público, el cual fue ocupado por militantes y simpatizantes de la Concertación, coalición que entrenó buena parte de sus cuadros en la sociedad civil, por lo que se podría hablar de un movimiento de agentes desde la sociedad civil hacia el aparato estatal (Delamaza, 2013).

Dicha situación permitió utilizar el sistema de patronazgo y cuoteo para recolonizar la administración pública heredada del régimen autoritario (Rehren, 2002; Siavelis, 2009), ${ }^{7}$ creando una red de policy makers con una orientación socialdemócrata, generando un contrapunto a la influencia y al terreno ganado por los Chicago Boys en la década de 1980 (Ramos y Scrollini, 2013).

El uso del cuoteo y el patronazgo como forma de recolonizar la administración pública chilena durante la transición hacia la democracia sumado a otros fenómenos condicionaron la instauración de un spoil system de circuito cerrado durante la década de 1990. Estos fenómenos fueron tres. Primero, la baja rotación en los gabinetes durante los gobiernos concertacionistas, la cual no solo da cuenta de una gran estabilidad gubernamental y coalicional, sino que también de la existencia de lógicas asentadas de distribución de poder respetando reglas de proporcionalidad con respecto al caudal electoral de los partidos de la Concertación, y la

\footnotetext{
${ }^{7}$ Ramos y Scrollini (2013) describen el sistema de patronazgo chileno como un juego de equilibrios entre los partidos luego de las elecciones, el cual implicaba una distribución de cargos en distintos niveles del gobierno en función del caudal electoral de los partidos. Esto va en la línea del concepto de cuoteo que Siavelis (2009) enumera como uno de los enclaves de transición chilenos y de los sistemas de clientelismo descritos por Grindle (2012).
} 
existencia de lógicas de integración vertical en las distintas reparticiones públicas (Altman, 2008; Rehren, 1992).

Segundo, la presencia de un círculo íntimo en la Concertación, en la línea de la tesis que apunta a la existencia de un partido transversal, lo que da cuenta de un fuerte liderazgo horizontal e interpartidario durante la década de 1990 (Joignant, 2011a, 2011b). Tercero y final, el hecho de que para acceder a altas posiciones en el ejecutivo fuese muy importante la cercanía con los partidos, la posesión de capital cultural y la participación en los centros de estudios de la coalición, ${ }^{8}$ mientras que para permanecer en aquellas posiciones se volvía absolutamente relevante acumular capital político siendo dirigente de partido (González-Bustamante, 2013), situaciones que dan cuenta de la necesidad de penetrar y luego afianzarse en el spoil system para acceder y permanecer en altos cargos gubernamentales.

El condicionamiento de un spoil system de circuito cerrado implicó un apoyo de la élite a procesos de modernización que no alteraran el cuoteo y el sistema de patronazgo. Sin embargo, desde el año 2000 empieza a cristalizarse un creciente malestar ciudadano hacia la Concertación debido a diversos casos de corrupción. A esta situación se suma una profunda molestia con el sistema de patronazgo, el cual empieza a ser mirado con gran recelo por la ciudadanía. Esto obliga a la coalición de gobierno a tomar una serie de medidas cuyo punto culmine es la instauración del SADP. Sin embargo, aquello no es el fin del cuoteo, pues muchas reparticiones se excluyen del sistema, y a pesar de que con el tiempo la cobertura de éste se incrementa gradualmente, también aumenta el uso de resquicios del sistema por parte de las autoridades que deciden los nombramientos, esto para generar nombramientos directos - supuestamente temporales - de forma indefinida. Entonces, la pregunta es, ¿el SADP en Chile apunta hacia la instauración de un servicio civil autónomo o más bien marca el paso de un spoil system de circuito cerrado a uno de circuito abierto?

\subsection{El surgimiento del Sistema de Alta Dirección Pública (SADP)}

Para responder con propiedad si el SADP es el camino a un servicio civil autónomo en Chile o es más bien un elemento de apretura en el contexto de un asentado spoil system, es importante examinar el contexto sociopolítico que marcó su surgimiento.

El año 2003 Chile atravesó una fuerte crisis política e institucional a causa de diversos casos de corrupción. Uno de los casos más difundidos fue el pago de sobresueldos a profesionales de alto nivel en el Ministerio de Obras Públicas (MOP) por medio de una triangulación con la empresa Gate. Esta situación, conocida como el caso MOP-Gate, fue una crisis que emergió ante un panorama de austeridad fiscal donde se volvió muy difícil pagar buenas remuneraciones a los directivos, por lo cual se creó un sistema informal e irregular que generaba

\footnotetext{
${ }^{8}$ Para profundizar sobre el impacto de los centros de estudios en el acceso a altas posiciones gubernamentales se recomienda revisar Olivares et al. (2014).
} 
sobresueldos (Waissbluth y Inostroza, 2006). Fue entonces que el gobierno de Ricardo Lagos (2000-06) y la oposición llegaron a un acuerdo político y legislativo que implicaba un paquete de iniciativas en materia de modernización y transparencia que contemplaban asuntos como el financiamiento de los partidos políticos, la regulación de las compras públicas, la instalación del SADP, entre otros temas de diversa índole (Lambertini y Silva, 2009).

Es entonces que se crea la Dirección Nacional del Servicio Civil (DNSC) y el SADP a través de la Ley № 19.882 aprobada en junio de 2003, lo cual constituye, a la fecha, el hito más importante para la profesionalización de la función pública en Chile. El SADP ha buscado restringir la discrecionalidad de las autoridades en el nombramiento de cargos directivos de exclusiva confianza, los cuales alcanzaban los 250 directivos por millón de habitantes, cifra muy superior a los 30 de Estados Unidos o los 1,3 de Inglaterra (Costa y Waissbluth, 2007). Cabe señalar que en el año 2003 existía un diagnóstico compartido por expertos y centros de estudios con respecto al exceso de altos cargos designados por exclusiva confianza y no por mecanismos de selección con base en méritos (Grindle, 2012; Lambertini y Silva, 2009). Una premisa básica para la instalación del sistema fue que los cargos relacionados con la definición de políticas públicas debían mantenerse fuera del ámbito del SADP, mientras que los cargos que tenían un rol principalmente ejecutivo debían entrar al sistema (Lambertini y Silva, 2009).

La DNSC está excluida del sistema, pues posee un director cuyo nombramiento es de exclusiva confianza del presidente de la República. El director de la DNSC preside el Consejo de Alta Dirección Pública (CADP), órgano autónomo integrado por cuatro miembros elegidos mediante designación presidencial con la ratificación del Senado. Los miembros del CADP son nombrados por seis años en duplas alternadas y no se pueden remover. A pesar de requerir aprobación del Senado, este consejo no está compuesto por operadores de partidos políticos, pues los consejeros han sido y son expertos en temas de administración de personal y/o políticas públicas, ya sea en el sector público o en el sector privado (Waissbluth y Inostroza, 2006). De hecho, el CADP ha funcionado como un órgano colegiado que progresivamente ha buscado obtener mayor autonomía, convirtiéndose en un férreo defensor del SADP (Lambertini y Silva, 2009).

El SADP se implementó en una primera instancia para los dos primeros niveles jerárquicos de un centenar de servicios públicos. ${ }^{9}$ Antes de la implementación del sistema, los cargos de primer nivel jerárquico eran designados discrecionalmente por el presidente de la República, mientras que los de segundo y tercer nivel jerárquico eran designados por las autoridades nombradas en los cargos de primer nivel. Aquí se aplicaba fuertemente la lógica de patronazgo o cuoteo con elementos de integración vertical que aseguraban nombramientos cruzados entre miembros de distintos partidos de la coalición. Esta situación, si bien positiva

\footnotetext{
${ }^{9}$ El primer nivel jerárquico son los jefes de servicios públicos, el segundo son subalternos directos (directores regionales o jefes de divisiones importantes de la organización). El SADP no contempla a los ministros, subsecretarios, intendentes y secretarios regionales ministeriales, los cuales son cargos cuyo nombramiento es político.
} 
desde una perspectiva de buena gobernanza y estabilidad coalicional, fue repudiada de forma creciente por la ciudadanía.

Los cargos que se concursan a través del SADP siguen siendo de confianza, debido a que el presidente de la República puede solicitar en cualquier momento la renuncia, ya sea por mal desempeño o por pérdida de confianza. Estos cargos tienen una duración de tres años renovables sin concurso hasta por dos oportunidades, además son de dedicación exclusiva y tienen asociada una indemnización por petición de renuncia o no renovación. También cuentan con una asignación especial que puede ser hasta del 100\% de su salario base (Costa y Waissbluth, 2007).

El proceso de selección se inicia cuando existe un cargo vacante en alguno de los servicios asociados al sistema, luego el perfil del cargo es aprobado por el consejo y se realiza un reclutamiento por avisaje en distintos medios o por head hunting. ${ }^{10}$ Posteriormente, las empresas encargadas realizan un análisis preliminar de los candidatos y generan un listado con una o dos decenas de candidatos preseleccionados, los cuales son entrevistados por el consejo o por un comité de selección (Costa y Waissbluth, 2007). El que sea el consejo o un comité de selección compuesto por integrantes del mismo consejo y del ministerio o servicio público del cargo a proveer, depende del nivel jerárquico del cargo que se está concursando — cuando se trata de un cargo de primer nivel jerárquico aplica el consejo- - Luego se generan ternas, cuaternas, o quinas, para que la autoridad correspondiente procese el nombramiento definitivo, eligiendo de forma discrecional e incluso pudiendo desestimar el proceso y solicitar que se inicie nuevamente. Incluso después del nombramiento la autoridad puede despedir al alto directivo cuando lo estime conveniente e iniciar un nuevo proceso. Este modelo garantiza que los cargos sigan siendo de confianza, pero se preocupa de establecer estándares mínimos de idoneidad en cuanto a las capacidades técnicas de los candidatos, en definitiva, funciona como un filtro.

El SADP contó con el apoyo del gobierno de Ricardo Lagos (2000-06), además, durante el primer gobierno de Michelle Bachelet (2006-10) se apresuró la ampliación de la cobertura del sistema debido al caso Chiledeportes, otro escándalo de corrupción que consistió en un desvío de fondos públicos hacia organizaciones sociales de dudosa procedencia. Esta expansión progresiva en el tiempo y en ocasiones acelerada por ventanas de oportunidad, ha hecho que el sistema chileno sea considerado como una política pública intertemporal, pues ha logrado sobrevivir a cambios de gobierno y de coalición gobernante (Ramos y Scrollini, 2013). Sin embargo, se aprecia un frecuente uso de discrecionalidad basada en confianza política sustentada en ciertos resquicios del sistema (Grindle, 2012).

El incremento en el uso de resquicios del sistema tiende a convertir al SADP en un simple productor de ternas que muchas veces son desestimadas. Estos resquicios dicen relación

\footnotetext{
${ }^{10}$ Costa y Waissbluth (2007) señalan que el perfil es un elemento clave. En Chile se ha seguido la tendencia de poner énfasis en la selección con base a un reducido número de competencias clave, tales como la visión estratégica, la capacidad gerencial, las habilidades emocionales y la relación con el entorno, los conocimientos técnicos, manejo de medios de comunicación y manejo del idioma inglés. Para más detalle sobre esto véase Araya-Moreno, BurgosBravo y Ganga Contreras (2012).
} 
con una aplicación discutible del artículo 59 de la ley, en virtud del cual se han realizado nombramientos temporales en cargos de alto nivel sin pasar por concurso (Lambertini y Silva, 2009). Un hecho que agrava esta situación es que se ha encontrado la forma de convertir esos nombramientos temporales en permanentes desechando una y otra vez las ternas propuestas por el sistema generando un bypass. Ramos, Scrollini y Solórzano (2012) señalan que en Chile los altos directivos públicos se vieron amenazados durante el gobierno de Sebastián Piñera (2010-14), el cual registró cerca de un $42 \%$ de despidos en el primer nivel jerárquico, supliendo esos cargos con subrogantes eternos rechazando ternas sucesivamente.

A pesar de este problema, el sistema presenta un buen funcionamiento. A junio de 2015 la concursabilidad llega a 115 servicios públicos del gobierno central cuyos cargos son adscritos y a 230 organismos e instituciones públicas cuyos cargos son no adscritos y utilizan el SADP como mecanismo de selección. Todo este significa que se han incorporado 1.256 cargos al sistema: 949 cargos de servicios adscritos y 307 cargos de otros organismos públicos no adscritos.

\section{Método}

\subsection{Análisis de los nombramientos de altos directivos de primer nivel jerárquico}

Este trabajo busca analizar los principales factores para el nombramiento como alto directivo público titular en el primer nivel jerárquico durante el período 2003-13 en los principales ministerios chilenos. La hipótesis central de este trabajo es que en Chile, el ser hombre, poseer capital político, tener un elevado nivel educacional, es decir, contar con magíster o doctorado, poseer una trayectoria profesional previa en el sector público y haber estudiado en una universidad tradicional, facilitan el nombramiento como alto directivo público titular.

El diseño utilizado es de tipo longitudinal pues se analizan en conjunto los casos de nombramientos realizados durante el período 2003-13. El trabajo se aborda desde una dimensión exploratoria, pues si bien se realiza un análisis estadístico descriptivo de los casos de la muestra - concursos y nombramientos- que se complementa con modelos de regresión logística (logit) para evaluar los factores que resultan determinantes para obtener un nombramiento como titular del SADP, los resultados no son concluyentes, principalmente por la precisión limitada de la muestra utilizada.

Considerando que la muestra es pequeña, los modelos estadísticos se construyen solo con tres variables independientes (covariables) para así seguir la regla de Freeman (1987) y trabajar con más de $(10) *(n+1)$ observaciones, donde $n$ corresponde a las covariables del modelo. Además se trabaja con un bootstrap (remuestreo) con base en el método de intervalo corregido para sesgo acelerado (BCa) (Efron, 1987). Este método es frecuentemente utilizado para evaluar la estabilidad y congruencia de análisis factoriales (Chan et al., 1999; Scott, Thompson y Sexton, 1989) o evaluar los índices de ajuste de los modelos de estructuras de covarianza (Bollen y Stine, 1992). 


\subsection{Precisión de la muestra}

Se trabaja con una muestra no probabilística compuesta por los directivos públicos de primer nivel jerárquico nombrados en los ministerios de alta importancia política. La muestra se compone de 45 casos (nombramientos) que se distribuyen tal como se indica en la tabla 1. La selección de los ministerios fue realizada con base en las categorías de Escobar-Lemmon y Taylor-Robinson (2005), quienes jerarquizaron los ministerios de América Latina a partir del grado de participación de las decisiones que toman dentro de los sistemas políticos. Estas autoras diferencian entre ministerios de alta, media y baja importancia.

Tabla 1

Tipos de ministerio y nombramientos 2003-13

\begin{tabular}{|cc|}
\hline Ministerio & № de nombramientos \\
\hline Interior & 6 \\
Hacienda & 17 \\
Economía & 15 \\
Defensa & 2 \\
Relaciones Exteriores & 5 \\
\hline
\end{tabular}

Fuente: Elaboración propia a partir de datos de la Resolución Exenta № 1.732 (19/12/2013).

La identificación de estos casos se realizó con base en información de concursos y nombramientos proporcionada por el Servicio Civil de Chile para ser utilizada en esta investigación. La información fue complementada con datos extraídos desde dos fuentes: los portales de transparencia de cada Web institucional y una Resolución Exenta del Servicio Civil de Chile con información sobre altos directivos de primer nivel jerárquico nombrados desde el año 2003 a diciembre de 2013. Se trata de la Resolución Exenta № 1.732 (19/12/2013) del Servicio Civil de Chile, que da respuesta a una solicitud de información pública ingresada el 23 de noviembre de 2013 por Ley de Transparencia.

La muestra con la que se trabaja cubre un $22 \%$ de los nombramientos realizados en instituciones adscritas y no adscritas al SADP vía concurso para el período 2003-13. Si bien la muestra contempla 45 nombramientos, éstos recaen solo en 41 personas, es decir, hay cuatro individuos que repiten nombramientos durante el período estudiado.

\section{Resultados}

\subsection{Características de los concursos realizados}

Para los concursos desarrollados entre 2003-13, en los cinco ministerios analizados, el Servicio Civil de Chile reporta la postulación de 6.214 personas: $83,4 \%$ hombres $(n=5.185)$ y $16,6 \%$ mujeres $(n=1.029)$. El promedio de edad de los postulantes fue de 43 años. 
Considerando que el proceso es confidencial, solo ha sido posible recuperar datos de la procedencia laboral del 56,4\% de los casos $(n=3.504)$, de los cuales un $33,4 \%(n=1.172)$ proviene desde el mismo sector público, mientras que un 66,6\% ( $n=2.332$ ) proviene del sector privado.

Por otra parte, el promedio de días desde la vacancia hasta la solicitud de inicio de concurso asciende a dos meses aproximadamente (60 días). Posteriormente, desde la solicitud de inicio de concurso a la publicación de éste, el tiempo promedio asciende a casi tres meses (82 días). Por su parte, el proceso de conformación de nóminas para la decisión de la autoridad también ronda los tres meses en promedio (85 días). Finalmente, el tiempo promedio que toma la autoridad para decidir el nombramiento es poco más de un mes (36 días). La suma de estos plazos nos ofrece un panorama del tiempo que transcurre desde la vacancia de un cargo hasta su nombramiento, el cual asciende a ocho meses y medio aproximadamente (263 días).

A continuación (gráfico 1) se presenta un gráfico que muestra la relación entre la cantidad de postulantes y la duración de los concursos realizados.

\section{Gráfico 1}

Scatterplot de cantidad de postulantes y duración de los concursos

realizados 2003-13

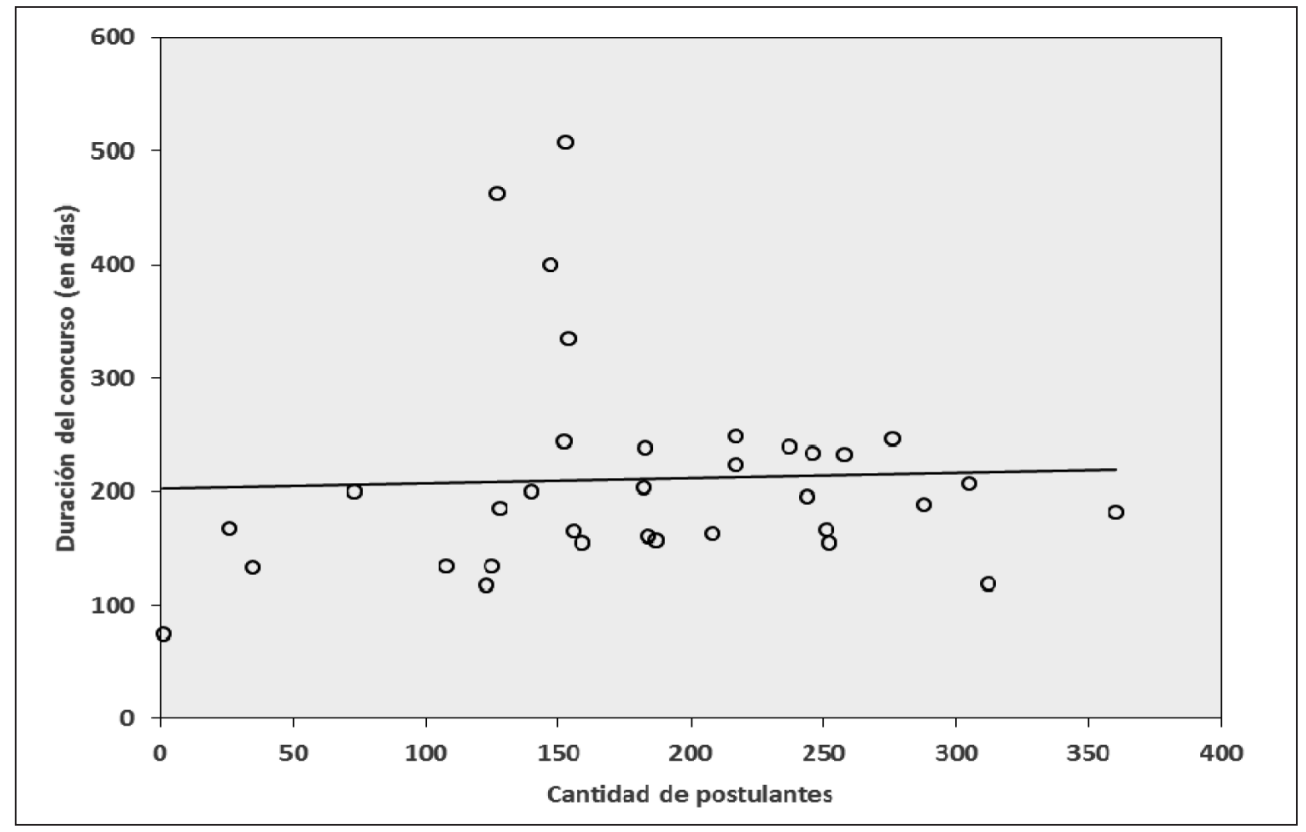

Fuente: Elaboración propia a partir de datos proporcionados por Rodrigo Egaña, Director Nacional del Servicio Civil, el año 2014.

No se aprecia una relación lineal entre la cantidad de postulantes y la duración del concurso, lo que sugiere que eventuales retrasos en los nombramientos no tienen que ver con la capacidad del sistema para procesar y evaluar postulaciones. 


\subsection{Características de los directivos titulares y provisionales transitorios}

Uno de los primeros elementos que llama la atención en la muestra de directivos titulares y provisionales transitorios $(n=45)$ es la disparidad de sexo. El número de hombres $(75,6 \%$; $n=34)$ supera considerablemente a las mujeres $(24,4 \% ; n=11)$. Dado que los cargos que se analizan son de confianza directa del presidente de la República, este antecedente es una mala señal respecto a los avances en igualdad de género que se han promovido en Chile durante la última década.

Por otra parte, es posible identificar un alto grado de profesionalización expresado en la acumulación de capital cultural institucionalizado, es decir, credenciales académicas. El 80\% $(n=36)$ posee magíster — varios de ellos incluso poseen dos o tres-; y cinco casos $(11,1 \%)$ poseen el grado de doctor o son candidatos para su eventual obtención.

Con respecto a la universidad de procedencia, se puede apreciar un alto número de personas que vienen de universidades que en Chile son consideradas tradicionales: $42,2 \%$ $(n=19)$ de la Universidad de Chile; y 24,4\% $(n=11)$ de la Pontificia Universidad Católica de Chile. En Chile se denomina como universidades tradicionales a aquellas creadas antes de 1982, año en que se liberaliza dicho sector permitiendo la aparición de nuevos actores, principalmente privados. Además existe una alta concentración con respecto a las áreas de las carreras profesionales: $33,3 \%(n=15)$ de los casos corresponden al área de las ciencias sociales; $64,4 \%(n=29)$ son profesionales de economía, administración o ingeniería; y el resto corresponde a oficiales en retiro de las Fuerzas Armadas.

En relación a la forma de ingreso a los cargos de primer nivel jerárquico es posible establecer las siguientes categorías: (a) nombramiento sin concurso y provisionales transitorios $22,2 \%(n=10)$; (b) nombramiento provisional transitorio y posterior nombramiento titular $13,3 \%(n=6) ;{ }^{11}$ y (c) nombramiento como titular de alta dirección 64,4\% $(n=29)$.

Con respecto al sector de donde provienen los funcionarios seleccionados para los cargos de primer nivel jerárquico, un 35,6\% $(n=16)$ proviene del sector privado, por otra parte, un $64,4 \%(n=29)$ proviene del sector público. Es importante destacar que para este análisis se consideró el último trabajo desempeñado antes de ocupar el cargo.

$\mathrm{Al}$ analizar las salidas del cargo es importante destacar que éstas se concentran en el gobierno de Sebastián Piñera (2010-14). El presidente Piñera es el primer gobernante de derecha desde el retorno a la democracia en 1990, por esta razón buscó imponer un sello diferenciador en su gestión, lo que significó, entre otras cosas, la remoción de muchos funcionarios que fueron seleccionados durante los gobiernos de la Concertación.

Finalmente, con respecto al capital político, solo ha sido posible identificar tres casos $(6,7 \%)$ que tienen alguna militancia activa, adhesión o cercanía pública reconocida con un partido político.

\footnotetext{
${ }^{11}$ Fueron nombrados de forma provisional transitoria, pero posteriormente —en menos de un año- ganaron el concurso en el SADP.
} 
En suma, y considerando las variables de esta investigación, es posible señalar que el directivo público de los ministerios más importantes en Chile entre los años 2003 y 2013 es un hombre con un promedio de edad de 43 años, que proviene mayoritariamente del sector público y con credenciales académicas relevantes.

\subsection{Factores que determinan el nombramiento de un alto directivo}

A continuación se presentan modelos estadísticos de regresión logística (logit) para evaluar los factores que determinan el nombramiento de altos directivos. La variable dependiente es el nombramiento como titular del SADP, los nombramientos provisionales transitorios se consideran como casos que no verifican la variable dependiente. Cabe señalar que se realizaron todas las modelaciones lógicamente posibles con tres covariables por el tamaño limitado de la muestra, solo se presentan los modelos con significación estadística. Por otra parte, la bondad de ajuste de los modelos no es muy alta pues los pseudo- $R^{2}$ se ubican cerca del 20\%.

En los modelos se constata que el único factor significativo es el capital político, sin embargo, tiene un efecto negativo, es decir, poseer capital político disminuye las probabilidades de ser seleccionado. Sorprendentemente el nivel educacional o la experiencia previa en el sector público no resultan estadísticamente significativas. Ahora bien, los modelos no arrojan mucha claridad sobre los nombramientos en el SADP, ante esto resulta recomendable incorporar más casos u observaciones y controlar la modelación con otras variables independientes que permitan mejorar el ajuste de las regresiones.

Tabla 2

Modelos de regresión logística para factores de nombramiento como titular del Sistema de Alta Dirección Pública en Chile (2003-13)

\begin{tabular}{|c|c|c|c|c|}
\hline & Modelo 1 & Modelo 2 & Modelo 3 & Modelo 4 \\
\hline $\begin{array}{l}\text { Sexo } \\
1=\text { Hombre }\end{array}$ & $\begin{array}{c}0,916 \\
(-1,034) \\
(3,057)\end{array}$ & $\begin{array}{l}0,929 \\
(-1,139) \\
(3,184)\end{array}$ & $\begin{array}{c}0,915 \\
(-20,302) \\
(21,927)\end{array}$ & - \\
\hline $\begin{array}{l}\text { Capital político } \\
1=\text { Militancia o adhesión }\end{array}$ & $\begin{array}{l}-22,152 * * \\
(-23,873) \\
(-21,124)\end{array}$ & $\begin{array}{l}-21,945^{* *} \\
(-23,723) \\
(-20,687)\end{array}$ & $\begin{array}{l}-21,987 * * * \\
(-22,943) \\
(-21,223)\end{array}$ & $\begin{array}{l}-21,692 * * \\
(-23,255) \\
(-20,692)\end{array}$ \\
\hline $\begin{array}{l}\text { Nivel educacional } \\
1 \text { = Título profesional; } \\
2 \text { = Magíster; } 3 \text { = Doctorado }\end{array}$ & - & $\begin{array}{c}0,604 \\
(-1,244) \\
(3,304)\end{array}$ & - & - \\
\hline
\end{tabular}

Continua 


\begin{tabular}{|lcccc|}
\hline & Modelo 1 & Modelo 2 & Modelo 3 & Modelo 4 \\
\hline $\begin{array}{l}\text { Trayectoria } \\
\text { profesional previa }\end{array}$ & 0,413 & & & 0,170 \\
$1=$ Sector público & $(-1,471)$ & - & - & $(-1,705)$ \\
Universidad pregrado & $(2,004)$ & & & $(1,735)$ \\
$1=$ Tradicional & & & $-0,896$ & $-0,821$ \\
& - & - & $(-2,464)$ & $(-19,774)$ \\
Constante & $-0,117$ & $-1,021$ & $0,119)$ & $(0,390)$ \\
& $(-3,033)$ & $-5,282)$ & $(-1,269)$ & $1,252+$ \\
Observaciones & $(20,155)$ & $(2,570)$ & $(20,790)$ & $(22,065)$ \\
Bootstrap (IC $95 \%$ BCa) & 45 & 45 & 45 & 45 \\
Cox \& Snell R & 959 & 959 & 969 & 944 \\
Nagelkerke R2 & 0,169 & 0,179 & 0,189 & 0,163 \\
\hline
\end{tabular}

Fuente: Elaboración propia a partir de datos de la Resolución Exenta № 1.732 (19/12/2013).

Nota: $I_{95 \%}$ BCa inferior y superior entre paréntesis.

+ Significativo $p \leq 0,\left.1\right|^{*}$ Significativo $p \leq 0,\left.05\right|^{* *}$ Significativo $\left.p \leq 0,01\right)\left.\right|^{* * *}$ Significativo $p \leq 0,001$

Por otra parte, si bien los modelos son estadísticamente significativos y se verificó que no existe colinealidad para evitar inestabilidad en los resultados, es posible que existan ciertos errores en la modelación producto de la baja cantidad de observaciones de la muestra. Al utilizar la regla de Freeman (1987) se ha limitado cada modelación a un máximo de tres variables independientes (covariables), si bien esto es técnicamente correcto ha impuesto una restricción para el uso de variables indicadoras (dummy). Lo anterior puede provocar un error tipo II en el análisis, el cual se produce al "infraoptimizar" el ajuste del modelo por no incluir o indicar variables relevantes (Ortega y Cayuela, 2002). Esto constituye una fuerte limitante del análisis presentado.

\section{Discusión y conclusiones}

Como consecuencia de los resultados de los modelos estadísticos la hipótesis central de este trabajo se rechaza. Esto es porque ser hombre, poseer capital político, tener un elevado nivel educacional, contar con una trayectoria previa en el sector público y haber estudiado en una universidad tradicional, no son factores determinantes para conseguir un nombramiento como alto directivo público titular en el primer nivel jerárquico para el período 2003-13 en Chile. 
En este sentido, es oportuno interrogarse sobre la pertinencia del uso de modelos estadísticos para analizar los nombramientos en el SADP. En estudios recientes con foco en la competencia política el análisis estadístico permite entender como el capital político y la carrera tienen (o no) influencia en la competencia electoral, algunos ejemplos de esto para el caso chileno son el trabajo sobre diputados de Saldaña (2014) y el de consejeros regionales de González-Bustamante (2014). Sin embargo, para trabajos como este, y dada la naturaleza y características del SADP, eventualmente sería más consistente utilizar enfoques de investigación con base en el perfil de los actores, siguiendo la lógica de trabajos como el de Costa y Waissbluth (2007) y Araya-Moreno, Burgos-Bravo y Ganga Contreras (2012).

No obstante lo anterior, el análisis estadístico, con todas sus limitantes, permite vislumbrar ciertas tendencias. Como se utiliza una muestra no probabilística es imposible realizar inferencia estadística sobre un universo de referencia, que para este caso serían todos los nombramientos realizados por el SADP o al menos los de primer nivel jerárquico. Por esta razón es que se debe tener presente el carácter exploratorio de esta investigación. En este sentido, sería relevante verificar si estas tendencias van más allá del muestreo con base en las categorías de Escobar-Lemmon y Taylor-Robinson (2005), situación que permitiría hacer extensible estos hallazgos a la totalidad del SADP chileno siempre y cuando se aplique un muestreo probabilístico.

Cabe señalar que los modelos de regresión logística logran una bondad de ajuste relativamente baja. La varianza de la variable dependiente se mide en relación a los nombramientos titulares en contraste con nombramientos provisionales transitorios, no con respecto a los casos que no lograron el nombramiento en los concursos realizados. Esto último no fue posible de verificar ya que la identidad de aquellas personas no es información a la que se pueda acceder por temas relacionados con las normas chilenas de protección de datos personales.

La importancia de los descubrimientos realizados, a pesar de las limitaciones del muestreo y el carácter exploratorio de esta investigación, radica en que los hallazgos constituyen un barómetro de lo que ha estado sucediendo en un lapso considerable de tiempo en varias áreas gubernamentales de indudable relevancia. En general se puede vislumbrar que los nombramientos mediante el SADP no se relacionan con la posesión de capital político. Considerando el efecto negativo de la variable, pareciera que el capital político disminuye las posibilidades en el nombramiento, lo cual indicaría que el sistema tiene un fuerte sesgo hacia lo técnico.

No obstante, si bien pareciera que el capital político no se relaciona con los nombramientos en el SADP, este es un hecho con el cual hay que tener cierta precaución, en particular por la existencia de nombramientos provisionales transitorios. Con una autoridad política con intereses particulares este tipo de nombramientos pueden ser una oportunidad para convertir el SADP en un simple sistema generador de ternas que asegura capacidad técnica de personas que ocupan cargos de alta dirección. El riesgo de aquello es que el sistema sea solo un elemento de apertura en un tradicional spoil system sustentado por el patronazgo y el cuoteo que han imperado en el sistema político chileno. La preocupación por esta situación es algo que vuelve a resurgir con cada cambio de gobierno. 
Por último, un hallazgo interesante es que no se constata una relación lineal entre la cantidad de postulantes a los concursos y la duración de éstos, lo que sugiere que eventuales retrasos en los nombramientos no tienen que ver con la capacidad del sistema para procesar y evaluar postulaciones sino con la decisión final que recae en las autoridades electas democráticamente.

\section{Referencias}

ALCÁNTARA, Manuel. De políticos y política: profesionalización y calidad en el ejercicio público. Perfiles Latinoamericanos, n. 41, p. 19-44, 2013.

ALTMAN, David. Political Recruitment and Candidate Selection in Chile, 1990 to 2006: The Executive Branch. En: SIAVELIS, Peter M.; MORGENSTERN, Scott (Ed.). Pathways to Power: Political Recruitment and Candidate Selection in Latin America. University Park: The Pennsylvania State University Press, 2008. p. 241-270.

ANSELL, Christopher. Network Institutionalism. En: RHODES, R. A. W.; BINDER, Sarah A.; ROCKMAN, Bert A. (Ed.). The Oxford handbook of political institutions. New York: Oxford University Press, 2006. p. 75-89.

ARAYA-MORENO, Eduardo; BURGOS-BRAVO, Daniel; GANGA CONTRERAS, Francisco. Coincidencias y diferencias de la oferta y la demanda en la formación de directivos públicos: una mirada al caso chileno". Revista del Clad Reforma y Democracia, n. 53, p. 131-164, 2012.

ARDILA, Federico. La reforma de la administración pública: entre los paradigmas externos y las realidades nacionales. En: CONGRESO INTERNACIONAL DEL CLAD SOBRE LA REFORMA DEL ESTADO Y LA ADMINISTRACIÓN PÚBLICA, VIII, Panamá, 2003.

BALLART, Xavier; RAMIÓ MATAS, Carles. Ciencia de la administración. Valencia: Tirant lo Blanch, 2000.

BOLLEN, Kenneth A.; STINE, Robert A. Bootstrapping goodness-of-fit measures in structural equation models. Sociological Methods Research, v. 21, n. 2, p. 205-229, 1992.

BOURDIEU, Pierre. Capital cultural, escuela y espacio social. México, DF: Siglo XXI Editores, $1997 / 2011$.

BOURDIEU, Pierre. El sentido práctico. Buenos Aires: Siglo XXI Editores, 1980/2009.

BOURDIEU, Pierre. Las estrategias de reproducción social. Buenos Aires: Siglo XXI Editores, 2011.

CHAN, Wai et al. An alternative method for evaluating congruence coefficients with Procrustes rotation: A bootstrap procedure. Psychological Methods, v. 4, n. 4, p. 378-402, 1999.

COSTA, Rossana; WAISSBLUTH, Mario. Tres años del Sistema de Alta Dirección Pública en Chile: balances y perspectivas. Documento de Trabajo, Serie Gestión, n. 94, 2007.

DELAMAZA, Gonzalo. De la elite civil a la elite política. Reproducción del poder en contextos de democratización. Polis, Revista Latinoamericana, v. 12, n. 36, p. 67-100, 2013. 
DELAMAZA, Gonzalo. Elitismo democrático, líderes civiles y tecnopolítica en la reconfiguración de las elites políticas. En: JOIGNANT, Alfredo; GÜELL, Pedro (Ed.). Notables, tecnócratas y mandarines: elementos de sociología de las elites en Chile (1990-2010). Santiago de Chile: Ediciones Universidad Diego Portales, 2011. p. 77-108.

ECHEBARRÍA, Koldo. Informe sobre la situación del servicio civil en América Latina. Washington, DC: Banco Interamericano de Desarrollo, 2006.

EFRON, Bradley. Better bootstrap confidence intervals. Journal of the American Statistical Association, v. 82, n. 397, p. 171-185, 1987.

ESCOBAR-LEMMON, María; TAYLOR-ROBINSON, Michelle M. Women ministers in Latin American government: when, where, and why? American Journal of Political Science, v. 49, n. 4, p. 829-844, 2005.

FREEMAN JR., Daniel H. Applied categorical data analysis. New York: Marcel Dekker Inc., 1987.

GÁRATE CHATEAU, Manuel. La revolución capitalista de Chile (1973-2003). Santiago de Chile: Ediciones Universidad Alberto Hurtado, 2012.

GARCÍA-PELAYO, Manuel. Burocracia y tecnocracia y otros escritos. Madrid: Alianza Editorial, 1982. GARRETÓN, Manuel Antonio. Chile 1997-1998: the revenge of incomplete democratization. International Affairs, v. 75, n. 2, p. 259-267, 1999.

GARRETÓN, Manuel Antonio. What society? What sociology? The Chilean post-democratization debate. Contemporary Sociology-a Journal of Reviews, v. 26, n. 5, p. 576-579, 1997.

GODOY, Óscar. La transición chilena a la democracia: pactada. Estudios Públicos, n. 74, p. 79-106, 1999.

GONZÁLEZ-BUSTAMANTE, Bastián. Elección directa de consejeros regionales 2013. Rendimiento del capital político, familiar y económico en una nueva arena electoral en Chile. Política, Revista de Ciencia Política, v. 52, n. 2, p. 49-91, 2014.

GONZÁLEZ-BUSTAMANTE, Bastián. Factores de acceso y permanencia de la élite política gubernamental en Chile (1990-2010). Política, Revista de Ciencia Política, v. 51, n. 1, p. 119-153, 2013.

GRINDLE, Merilee S. Jobs for the boys: patronage and the state in comparative perspective. Cambridge: Harvard University Press, 2012.

GUERRERO, Omar. El fin de la Nueva Gerencia Pública. Estado, Gobierno y Gestión Pública, n. 13, p. 55-22, 2009.

HECLO, Hugh; WILDAVSKY, Aaron. The private government of public money. London: Macmillan, 1974.

JOIGNANT, Alfredo. Tecnócratas, technopols y dirigentes de partido: tipos de agentes y especies de capital en las elites gubernamentales de la Concertación (1990-2010). En: JOIGNANT, Alfredo; GÜELL, Pedro (Ed.). Notables, tecnócratas y mandarines: elementos de sociología de las elites en Chile (1990-2010). Santiago de Chile: Ediciones Universidad Diego Portales, 2011a. p. 49-76. 
JOIGNANT, Alfredo. The politics of technopols: resources, political competence and collective leadership in Chile, 1990-2010. Journal of Latin American Studies, v. 43, n. 3, p 517-546, 2011 b.

KIM, Pan Suk. Desafíos de la capacidad pública en la era de una administración pública en evolución y reforma del gobierno. Gestión y Política, v. 16, n. 2, p. 511-537, 2007.

KINGDON, John. Agendas, alternatives, and public policies. Boston: Little, Brown \& Co., 1984.

LAMBERTINI, Gianni; SILVA, Ernesto. Hacia un perfeccionamiento del Sistema de Alta Dirección Pública. En: TOMICIC, Visnja; GARCÍA, Cristián (Ed.). Un mejor Estado para Chile: propuestas de modernización reforma. Santiago de Chile: Consorcio para la Reforma del Estado, 2009. p. 315-351.

MAILLET, Antoine. La construcción política de los mercados. Variedades de neoliberalismo en el Chile post-dictadura. Tesis (Doctorado) - Pontifica Universidad Católica de Chile y SciencesPo, Santiago de Chile, 2013.

MARCH, James G.; OLSEN, Johan P. Elaborating the "new institutionalism". En: RHODES, R. A. W.; BINDER, Sarah A.; ROCKMAN, Bert A. (Ed.). The Oxford handbook of political institutions. New York: Oxford University Press, 2006. p. 3-20.

OLIVARES, Alejandro et al. Los think tanks en el gabinete: una exploración del caso chileno (20062014). Revista de Sociología, n. 29, p. 37-54, 2014.

ORTEGA CALVO, Manuel; CAYUELA DOMÍNGUEZ, Aurelio. Regresión logística no condicionada y tamaño de muestra: una revisión bibliográfica. Revista Española de Salud Pública, v. 76, n. 2, p. 85-93, 2002.

PLISCOFF, Cristián. Modernización de la gestión pública en el primer tiempo. Avances y retrocesos. Agenda Pública, n. 11, p. 10-22, 2008.

QUERMONNE, Jean-Louis. La organización administrativa del Estado. Barcelona: Escola d'Administració Pública de Catalunya, 1995.

RAMIÓ MATAS, Carles; SALVADOR, Miquel. Servicio civil en América Latina: reflexiones y propuestas tentativas. Documentos y Aportes en Administración Pública y Gestión Estatal, n. 6, p. 63-90, 2005.

RAMOS, Conrado; SCROLLINI, Fabrizio. Los nuevos acuerdos entre políticos y servidores públicos en la alta dirección pública en Chile y Uruguay. Revista Uruguaya de Ciencia Política, v. 22, n. 1, p. 11-36, 2013.

RAMOS, Conrado; SCROLLINI, Fabrizio; SOLÓRZANO, Fernanda. El tímido e incierto camino de la Alta Dirección Pública en el Uruguay. Aprendizajes a partir de los casos de Chile y Nueva Zelanda. Montevideo: Universidad de la Republica, 2012.

REHREN, Alfredo. Clientelismo político, corrupción y reforma de estado en Chile. En VALDÉS, Salvador (Ed.). Reforma de Estado. Volumen II: Dirección pública y compras públicas. Santiago de Chile: Centro de Estudios Públicos, 2002. p. 127-164.

REHREN, Alfredo. Liderazgo presidencial y democratización en el cono sur de América Latina. Revista de Ciencia Política, v. 14, n. 1-2, p. 63-87, 1992. 
RHODES, R. A. W. Old institutionalisms. En: RHODES, R. A. W.; BINDER, Sarah A.; ROCKMAN, Bert A. (Ed.). The Oxford handbook of political institutions. New York: Oxford University Press, 2006. p. 90-108.

SALDAÑA, Jorge. Carreras políticas de los diputados chilenos, 1989-2013: evolución y sus consecuencias para la representación política del país. Política, Revista de Ciencia Política, v. 52, n. 2, p. 127-155, 2014.

SCOTT, Randall L.; THOMPSON, Bruce; SEXTON, David. Structure of a short form of the questionnaire on resources and stress: a bootstrap factor analysis. Educational and Psychological Measurement, v. 49, n. 2, p. 409-419, 1989.

SIAVELIS, Peter. Enclaves de la transición y democracia chilena. Revista de Ciencia Política, v. 29, n. 1, p. 3-21, 2009.

SILVA, Patricio. In the Name of Reason: Technocrats and Politics in Chile. Pennsylvania: Pennsylvania State University Press, 2009.

VICHER, Diana. Reflexiones sobre las reformas neogerenciales ¿Hacia una nueva reforma administrativa? Revista Estado, Gobierno, Gestión Pública, n. 13, p. 53-85, 2009.

WAISSBLUTH, Mario; INOSTROZA, José. Reforma del servicio civil chileno. Santiago de Chile: Universidad de Chile, 2006. (Documento de Trabajo). Disponible en: <www.sistemaspublicos.cl/ wp-content/files_mf/1291208901Paper-Brasilia_Nov2006_FINAL_enero2007.pdf>. Acceso: 22 sept. 2013.

Bastián González-Bustamante es profesor adjunto e investigador asociado del Departamento de Gestión y Políticas Públicas de la Facultad de Administración y Economía de la Universidad de Santiago de Chile. Investigador del Programa de Estudios de Gobierno de la Universidad de Santiago de Chile. Magíster en ciencia política, administrador público y licenciado en ciencias políticas y gubernamentales por la Universidad de Chile. E-mail: bastian.gonzalez.b@usach.cl.

Alejandro Olivares L. es docente e investigador en el Instituto de Asuntos Públicos de la Universidad de Chile. Doctor (c) en ciencias sociales y magíster en ciencia política por la Universidad de Chile. Cientista político y licenciado en ciencia política por la Universidad Central de Chile. E-mail: aleolivares@iap. uchile.cl.

Pedro Abarca es analista de la Unidad de Desarrollo Estratégico del Servicio Nacional de Capacitación y Empleo de Chile. Administrador público y licenciado en ciencias políticas y gubernamentales por la Universidad de Chile. E-mail: pabarcab@um.uchile.cl.

Esteban Molina es consultor de la Unidad de Calidad y Control de Gestión de Topoland Ingeniería y Compañía Limitada. Administrador público y licenciado en ciencias políticas y gubernamentales por la Universidad de Chile. E-mail: emolinasaez@gmail.com. 